\section{REFERENCES}

Bayer, C. A. An explanation of developmental differences in the successive trials effect of the Poggendorff Illusion. Psychonomic Science, 1972, 26, 85-86.

Judd, C. H. Practice and its effects on the perception of illusions. Psychological R eview, 1902, 9, 27-39.

Langer, J. The representatin of perceptual phenomena: A comparison of nonverbal (linear) representations with linguistic coding. Unpublished doctoral dissertation, Clark University, 1962.

Leibowitz, H. W., \& Gwozdecki, J. The magnitude of the Poggendorff Illusion as a function of age. Child Development, $1967,38,573-580$.

Miller, A. An experimental study of the role of sensory-motor activity in the retention of verbal meaning. Unpublished doctoral dissertation, Clark University, 1959.

Pressey A. W Bayer, C. A., \& Kelm, H. The Poggendorff in schizophrenic patients. Schizophrenia, 1969, 1, 88-94.

Pressey, A. W., \& Sweeney, O. A variation of the Poggendorff
Illusion. Perceptual \& Motor Skills, 1969, 28, 883-886.

Pressey, A. W., \& Sweeney, O. Age changes in the Poggendorff ulusion as measured by a method of production. Psychonomic Science, 1970, 19, 100.

Wapner, S. \& Werner, H. Perceptual Developmenta: An investigation within the framework of sensory-tonic field theory. Worcester: Clark University Press, 1957.

Werner, $\mathrm{H}$. Comparative psychology of mental development. New York: Science Editions, 1961.

Werner, H., \& Kaplan, B. Symbol Formation. New York: Wiley, 1967.

\section{NOTE}

1. Appreciation is extended to G. Little, principal of Victoria School in Portage La Prairie, Manitoba, for his kind cooperation and the use of the school facilities during these studies.

\title{
Attenuation of novelty preference: Homeostatic arousal or retrograde amnesia?
}

\author{
J. L. MOTTIN and R. W. GATEHOUSE \\ University of Guelph, Guelph, Ontario, Canada
}

\begin{abstract}
Wistar rats habituated to one arm (either black or white; left or right) of a Y-maze and tested for novelty preference via a free choice to enter the novel or familiar maze arm, consistently preferred the novel route except when preexposed to ECS stimulation, Contrary to a previously favored hypothesis of homeostatic arousal, exposure to intense white noise $(94-102 \mathrm{~dB} ; 15 \mathrm{sec}-4 \mathrm{~h}$ ) failed to produce choice frequencies different from the preference for novelty exhibited under nonarousing control conditions. These results lend support to an alternative interpretation based on an assumed disruption of habituation processing.
\end{abstract}

Although a relatively large body of knowledge is accumulating about the physiological and anatomical correlates of noise pollution, relatively little is known about its psychological dimensions. In one of the few studies in the latter vein, Haywood and Wachs (1967) suggested that noise stimulation may alter the organism by arousing the information processing system beyond an optimal level of stimulation and inducing a return to equilibrium. Behaviorally, an organism so aroused by noise would tend to seek the familiar in preference to novel stimulus conditions (presumably novelty would induce only further arousal). The Haywood and Wachs experiment supported this view by demonstrating a reduction of choice behavior to chance level in rats exposed to intense white noise, while unexposed rats strongly preferred the novel choice.

While the homeostatic arousal hypothesis presents a

The authors would like to thank M. R. Denny for his comments and suggestions, and for sponsoring and taking the editorial responsibility for this paper. The study was supported by Research Advisory Board, University of Guelph Grant 694-13. new dimension to the possible psychological effects of noise, there are several problems to contend with. The hypothesis predicts a clear preference for the familiar, whereas Haywood and Wachs's manipulations failed to produce choice frequencies below chance levels, leaving open the possibility that the absence of any preference under noise conditions was the result of an interruption of habituation effects, creating an absence of "novelty choice." It should be noted that Haywood and Wachs referred to this as an alternative hypothesis. But no investigation of this alternative explanation has occurred, although Sheldon (1968) acknowledged the possible role of disruption in the effects of shock on novelty preference.

Moreover, the physical properties of the white noise stimulation remain undocumented, reference having been made only to psychological adjustments to levels "just less than that required to produce audiogenic seizures" (Haywood \& Wachs, 1967, Pp. 78). Precise replication of the noise manipulations thus remains extremely difficult given that the literature and pilot studies in our laboratory have failed to reveal threshold 
levels for audiogenic seizures in the rat when audio signals are presented in the manner described in the original study (remote speaker presentation). Even if subseizure threshold intensities could be demonstrated for the rat, the choice of such a level of stimulation is unfortunate since it is reasonable to assume that homeostatic arousal thresholds could be exceeded without approximating seizure thresholds, especially if noise and novelty arousal were synergetic.

The purpose of the present study was to initiate studies on the effects of noise stimulation, beginning with an attempt to replicate the Haywood and Wachs results. The hypothesis that increasing the level of arousing stimulation results in a decrement in the preference for novelty was tested in seven successive experiments whose results are found in Table 1.

\section{METHOD}

The general strategy was comparable to that reported by Haywood and Wachs (1967), that is, to habituate rats to one arm (either black or white; left or right) of the Y-maze, then to test their preference for the familiar arm as opposed to the unfamiliar arm on a free choice trial, with either noise or no noise interposed between habituation trials and the free choice trial.

\section{Subjects}

Forty-eight 90-day old male Wistar rats (Woodlyn Farms) were randomly assigned to be habituated to either the white-right (WR), white-left (WL), black-left (BL), or black-right (BR) color-position alleys of a standard Y-maze.

\section{Apparatus}

The basic apparatus was a Y-maze with interchangeable wooden maze arms modeled after Haywood and Wachs (1967). The grey start box was enclosed at one end, and the other end, which opened into the choice-arms area, could be closed off by a guillotine-type metal door. The startbox had a wedge-shaped extension which was cut in a manner that allowed for easy interchange of the maze arms. The arms of the maze (one black; one white) were open at the far end to allow subjects to exit directly onto a table top. The apparatus was mounted on rubber and placed on a table top within an Eckel (Model 1010D) acoustic booth.

The acoustic signals were generated by a Lafayette (Model 1432) white noise generator. The output was fed through a Lafayette (Model 1421) amplifier to a simple on-off toggle switch. The switch in turn was connected directly to a stand-mounted speaker (Acoustic Research Incorporated, Model AR-2ax). The speaker was placed above and at $45 \mathrm{deg}$ to the startbox entrance. A Bruel and Kjaer (B \& K) sound level meter (Model 2204) fitted with a 1/4-in condenser microphone (B \& K, $3165)$ was used to measure the signal intensities prior to the beginning of, and at the end of each experiment. The intensity of the signal at the startbox ending, where it opened onto the wedge-shaped floor extension, was set at $102 \mathrm{~dB}$ (re .0002 dynes $/ \mathrm{cm}^{2}$ ) in Experiment $\mathrm{I}$ at $94 \mathrm{~dB}$ in subsequent experiments.

\section{Procedure}

Experiment I. This replicated Haywood and Wachs's (1967) study in which they observed a decrement in novelty preference as a result of the presentation of $15 \mathrm{sec}$ of white noise immediately prior to access to the two arms of the Y-maze. Three habituation trials to one arm were presented in quick succession to all subjects. For the experimental group, habituation trials were immediately followed by $15 \mathrm{sec}$ of noise, presented in the startbox and terminated as the free-choice trial began. Controls were given the free-choice trial in the absence of prior noise stimulation. Sixteen rats were randomly assigned to either control or experimental groups, allotted equally across the four color-position conditions.

Experiment II. This replicated Experiment I with the exception that the 15-sec noise exposure occurred on both the habituation and the free choice trials. The 16 subjects from Experiment I were used for this experiment with control-experimental designations reversed and color-position altered during habituation trials.

Experiment III. This replicated Experiment II with the noise stimulation extended to 2-min exposures. Again subjects' designation as experimental or control were reversed and color position during habituation shifted.

Experiment IV. This replicated Experiment III with the exception that the animals were now preexposed to $3 \mathrm{~h}$ and $59 \mathrm{~min}$ of noise prior to the procedures used in Experiment II, i.e., a total of 4-h exposure. This was done to insure that the noise was producing more than temporary threshold shifts (TTS) or more than short-lived arousal. In this study a naive group of 16 subjects was used and assigned in the same manner as in Experiment I.

Experiment V. The experimenters reasoned that failure to replicate Haywood and Wachs's results might be due to the procedural difference of terminating the sound stimulus prior to a completed escape response (i.e., absolute exposure times). Therefore, this experiment attempted to examine this possibility by the use of naive subjects in two experimental groups and one control group (4 control subjects; Experimental Group 1, 4 subjects; Experimental Group 2, 8 subjects). Experimental Group 1, as in Experiment I, had the sound off after $15 \mathrm{sec}$ in startbox. Experimental Group 2 was exposed to noise until they had escaped into one of the end boxes (Haywood and Wachs's procedure). Control animals received no noise exposure.

Experiment VI. It was possible that stimulation offset might be more arousing than simple exposure duration. Therefore, in a further effort to produce homeostatic arousal by noise stimulation, Experiment VI incorporated 2-h noise exposure and a 30 -sec period of silence immediately before choice behavior. In this experiment, then, time in the startbox on the choice trial was 45 sec. The animals used in Experiment IV were used again with all 16 designated as experimentals.

Experimental VII. Although Hay wood and Wachs (1967) indicated that they used subconvulsive seizure level sounds in their experiments, they neglected to specify their sound levels (SPLs) and the procedures they followed to establish them. Consequently, exact replication was impossible. For some strains of mice, it has been known for some time that audiogenic seizures could be established at levels greater than $90 \mathrm{~dB}$. However, the establishment of seizure level intensities for rats has not been well documented. Furthermore, the present experimenters failed to establish overt audiogenic seizures at levels greater than $100 \mathrm{~dB}$ in several pilot studies done prior to this series of experiments. Since Haywood and Wachs did not make their data available, perhaps the decrements in novelty achieved by them were in fact due to the initiation of covert seizure activity. Haywood and Wachs acknowledged this possibility but referred to it only as an alternative hypothesis, i.e., that seizure activity produces a retrograde amnesia for familiar stimuli, in effect removing the novel-familiar choice. To examine this possibility, Experiment VII produced retrograde amnesia via a $15-\mathrm{mA}, 2$-sec electroconvulsive shock, rather than by attempting to approximate the unreported noise levels. The rats used were the same as those used in Experiments I, II, and III, thus completing counterbalancing for possible position-color preferences, i.e., each rat experienced each position-color 
combination. However, the absence of effects on the first three experiments led to the use of all 16 animals as experimentals.

\section{RESULTS AND DISCUSSION}

The results indicated that the rats consistently preferred the novel route or nonhabituated arm of the Y-maze, except when preexposed to ECS stimulation (Table 1). Behavioral persistence was independent of noise duration, noise offset parameters, and possible color-position preferences.

The attenuation of novelty preference by ECS stimulation (56\% novel entries) was independent of the first habituation condition to which the subjects were exposed in Experiment I (i.e., whether rats were first habituated on WR, WL, BR, BL) and the group (experimental or control) to which the subjects were assigned in the various experiments. The chance level responding observed was not indicative of avoidance of novelty as would be predicted by the homeostatic arousal assumption. Rather, ECS produced choice behavior indicative of an absence of "novelty choice," comparable to the Haywood and Wachs's results with white noise.

As the choice frequencies for experimental animals were highly similar in Experiments I, II, and III it was apparent that the duration manipulations had little effect on the subjects' behavior. For this reason and the fact that animals in I, II, III, and VII were the same and included a counterbalanced design, the experimental conditions were collapsed in order to compare noise interposition with ECS interposition and analyzed by means of a $Z$ test on proportions $(Z=3.07 ; p<.01)$. So analyzed, ECS stimulation resulted in a significant reduction in the preference for novelty stimulation as compared to that produced by noise.

Adjunctive reports by a naive experimental technician, of greater urination, defecation, and vocalizations in the experimental animals, indicated arousal-type distinctions between the controls and experimentals. These reports were not post hoc; but, as in the Haywood and Wachs study, no formal measures of arousal were obtained.

A parsimonious explanation for the chance level responding in the Haywood and Wachs's study is the hypothesis offered as an alternative by Haywood and Wachs. That is, intense stimulation may have served to erase the memory trace of the habituation trials or simply to disrupt organized behavior. The failure to produce novelty decrements under arousing stimulation in the present series of experiments would lend support to the utility of this alternative hypothesis. This interpretation is also in line with Haywood and Hunts's (1963) failure to produce novelty decrements via adrenaline produced arousal. That we replicated Haywood and Wachs's experimental results by procedures known to erase memory traces, further
Table 1

Frequencies of Novel Endbox Entries for the Seven Experiments $(N=16$ Per Experiment)

\begin{tabular}{|c|c|c|}
\hline & \multicolumn{2}{|c|}{$\begin{array}{l}\text { Choices of Novel } \\
\text { Stimulus Alley }\end{array}$} \\
\hline & \multicolumn{2}{|c|}{ Subjects } \\
\hline & $\begin{array}{l}\text { Experi- } \\
\text { mental }\end{array}$ & $\begin{array}{l}\text { Con- } \\
\text { trol }\end{array}$ \\
\hline \multicolumn{3}{|l|}{ Experiment I } \\
\hline $\begin{array}{l}15 \mathrm{sec} \text { noise in startbox } \\
\text { on test trial only }\end{array}$ & $8 / 8$ & $8 / 8$ \\
\hline \multicolumn{3}{|l|}{ Experiment II } \\
\hline $\begin{array}{l}15 \text { sec noise in startbox } \\
\text { on all trials }\end{array}$ & $7 / 8$ & $8 / 8$ \\
\hline \multicolumn{3}{|l|}{ Experiment III } \\
\hline $\begin{array}{l}2 \text { min noise in startbox } \\
\text { on all trials }\end{array}$ & $8 / 8$ & $8 / 8$ \\
\hline \multicolumn{3}{|l|}{ Experiment IV } \\
\hline $\begin{array}{l}4 \mathrm{~h} \text { total sound including } 15 \mathrm{sec} \\
\text { startbox exposures on all trials }\end{array}$ & $8 / 8$ & $7 / 8$ \\
\hline \multicolumn{3}{|l|}{ Experiment $\mathrm{V}$} \\
\hline $\begin{array}{l}\text { Controls: held } 15 \mathrm{sec} \text { with no } \\
\text { noise on training and test trials }\end{array}$ & & $4 / 4$ \\
\hline $\begin{array}{l}\text { Experimental Group } 1: 15 \mathrm{sec} \\
\text { noise on test trial only prior } \\
\text { to release }\end{array}$ & $4 / 4$ & \\
\hline $\begin{array}{l}\text { Experimental Group } 2: \text { as in } \\
\text { Group } 1 \text { but sound extended until } \\
\text { choice completed }\end{array}$ & $8 / 8$ & \\
\hline \multicolumn{3}{|l|}{ Experiment VI } \\
\hline $\begin{array}{l}2 \mathrm{~h} \text { sound including } 3 \text { training } \\
\text { trials and } 15 \mathrm{sec} \text { on test trial; } \\
30 \mathrm{sec} \text { silence and release }\end{array}$ & $16 / 16$ & $0^{*}$ \\
\hline \multicolumn{3}{|l|}{ Experiment VII } \\
\hline $\begin{array}{l}\text { ECS after training trials; no noise } \\
\text { on test trial }\end{array}$ & $9 / 16$ & $0^{*}$ \\
\hline
\end{tabular}

*In Experiments VI and VII, all subjects were used as experimentals.

suggests priority for the alternative hypothesis. However, the fact that Haywood and Wachs could produce similar effects with low shock levels and shock incongruity suggests a simple disruption of preference behavior without the need to posit disruption of memory traces of habituation. Finally, it should be pointed out that true preference for the familiar has been induced when intense shock has been used (Sheldon, 1968; Thompson \& Higgins, 1958).

\section{REFERENCES}

Haywood, H. C., \& Hunt, J. McV. Effects of epinephrine upon novelty preference and arousal. Journal of Abnormal and Social Psychology, 1963.

Haywood, H. C., \& Wachs, T. D. Effects of arousing stimulation upon novelty preference in rats. British Journal of Psychology, 58, 77-84, 1967.

Sheldon, M. H. The effect of electric shock on rat's choice between familiar and unfamiliar maze arms: A replication. Quarterly Journal of Experimental Psychology, 20, 400-404, 1968.

Thompson, W. R., \& Higgins, W. H. Emotion and organized behaviour: Experimental data bearing on the Leeper-Young controversy. Canadian Journal of Psychology, 12, 61-68, 1958.

(Received for publication October 21, 1974.) 